\title{
INSTRUMENTOS ECONÓMICOS PARA LA GESTIÓN DE LA CALIDAD DEL AIRE: APLICACIÓN DE IMPUESTOS Y PERMISOS DE EMISIÓN EN CHILE*
}

\section{Cristóbal de la Maza}

Fundación Chile

\section{Paulina Schulz}

M. del Medio Ambiente

\section{Sandra Briceño}

M. del Medio Ambiente

\section{Julio Recordón}

M. del Medio Ambiente

\section{Isabel Rojas}

M. del Medio Ambiente

Luis Abdón Cifuentes

P. Universidad Católica

Cristóbal de la Maza Guzmán. Ingeniero civil de industrias, P. Universidad Católica de Chile. Consultor en Fundación Chile. Estudiante de $\mathrm{PhD}$ en el Departamento de Ingeniería y Políticas Públicas de Carnegie Mellon University. Email: cristobal.delamazag@gmail.com.

Sandra Briceño Pérez. Economista, Universidad Nacional de Colombia. Ms.C. Economía de recursos naturales y del medio ambiente, Universidad de Concepción. Trabaja en el Departamento de Economía Ambiental del Ministerio del Medio Ambiente de Chile (MMA). Email: sandra.briceno@gmail.com.

Isabel Rojas Astorga. Economista, Universidad de Chile. Trabaja en el Departamento de Economía Ambiental del MMA. Email: isabel.rojas.astorga@gmail.com.

Paulina Schulz Antipa. Ingeniero civil de industrias, P. Universidad Católica de Chile. Master en economía y finanzas, Centro de Estudios Monetarios y Financieros, Madrid. Trabaja en el Departamento de Economía Ambiental del MMA. Email: paulina.schulz@gmail.com.

Julio Recordón Hartung. Abogado, P. Universidad Católica de Valparaíso. Trabaja en la División Jurídica del MMA. Email: jrecordh@gmail.com.

Luis Abdón Cifuentes. PhD en Ingeniería y Políticas Públicas de Carnegie Mellon University. Profesor asociado de la Escuela de Ingeniería de la P. Universidad Católica de Chile. Email: lac@ing.puc.cl.

* Los autores señalan que los puntos de vista desarrollados en este artículo son estrictamente personales y no representan, en absoluto, a ninguna de las instituciones donde hoy trabajan. Agradecen, además, la colaboración de Carlos Chávez, Ricardo Katz, Raúl O'Ryan y Lucas Sierra en el desarrollo de este trabajo. También mencionan la deuda con los árbitros anónimos por sus valiosos comentarios. Se reconoce, por último, el apoyo de la Subsecretaria de Medio Ambiente durante el año 2013. Asumen, sin embargo, que todo error es de su responsabilidad. 
RESUMEN: La contaminación atmosférica es una de las principales preocupaciones en materia ambiental en Chile. A nivel internacional existe un interés creciente por el uso de instrumentos económicos como medio de control, debido a su mayor eficiencia y flexibilidad. El presente artículo presenta el desempeño de dos instrumentos económicos aplicables en planes de prevención o descontaminación: impuestos a las emisiones y permisos de emisión transables. El análisis evalúa el desempeño de estos instrumentos de acuerdo con su eficiencia económica y otras consideraciones de índole jurídica. A su vez, se discuten los principales elementos de ambos instrumentos en una aplicación práctica en Concepción metropolitano, evidenciando la importancia de su habilitación legal.

Palabras clave: Contaminación atmosférica; permisos de emisión transables; impuesto a las emisiones; plan de descontaminación.

RECIBIDO: noviembre 2013; ACEPTADO: julio 2014.

\title{
ECONOMIC INSTRUMENTS TO MANAGE AIR QUALITY: THE USE OF TAXES AND EMISSION PERMITS IN CHILE
}

\begin{abstract}
Air pollution is a major environmental concern in Chile. There is a growing international interest in the use of economic instruments to abate pollution considering they are more efficient and flexible. This study looks at the performance of two economic instruments used in prevention or decontamination plans: emissions taxes and tradable emission permits. The paper evaluates the performance of these instruments based on their economic efficiency and other legal considerations. The main elements of both schemes are also discussed in a case study on Greater Concepcion, which shows the importance of making these instruments law.
\end{abstract}

KEYwords: Air pollution, tradable emission permits (TEP), emission taxes, decontamination plan.

RECEIVED: November 2013; ACCEPTED: July 2014.

\section{INTRODUCCIÓN}

$E^{\prime}$ n Chile, la contaminación atmosférica ha sido una de las principales preocupaciones en materia ambiental. La necesidad de su regulación obedece esencialmente al impacto que tienen contaminantes sobre la salud de las personas, lo que se manifiesta en casos de morbilidad y mortalidad asociados a enfermedades cardiorrespiratorias y sus respectivas consecuencias en el bienestar social. Ya en el año 1961 se dictó la primera normativa específica en esta materia a través del Decreto Supremo N. ${ }^{\circ}$ 144, del Ministerio de Salud, "Normas para evitar 
emanaciones o contaminantes atmosféricos de cualquier naturaleza". Posteriormente, en 1978, se dictó la Resolución N. 1215 del mismo ministerio, "Normas sanitarias mínimas destinadas a prevenir y controlar la contaminación atmosférica".

Desde la promulgación de la Ley N. ${ }^{\circ} 19.300$ sobre bases generales del medio ambiente, el año 1994, se han establecido normas de calidad primaria que establecen las concentraciones atmosféricas máximas para $\mathrm{Pb}, \mathrm{MP}_{2,5}, \mathrm{NO}_{2}, \mathrm{CO}, \mathrm{MP}_{10}, \mathrm{SO}_{2} \mathrm{y} \mathrm{O}_{3}$. A su vez, se cuenta con una variada gama de instrumentos de gestión ambiental, que permiten abordar el problema de la calidad del aire de una manera integral. Los instrumentos establecidos en la Ley N. ${ }^{\circ} 19.300$, modificada por la Ley N. ${ }^{\circ} 20.417$, son, entre otros: educación e investigación; evaluación ambiental estratégica; sistema de evaluación de impacto ambiental; normas de calidad ambiental; normas de emisión; y planes de manejo, prevención o descontaminación.

Con el fin de dar cumplimiento a las normas de calidad establecidas se ha desarrollado una serie de Planes de Prevención Atmosférica (PPA) y Planes de Descontaminación Atmosférica (PDA), que consideran el cumplimiento gradual de las normas establecidas, principalmente a través de exigencias de tipo comando y control. Las dos principales formas de comando y control utilizadas corresponden a estándares tecnológicos y a estándares de desempeño. Los primeros establecen el uso de una tecnología de abatimiento específica (e.g. lavador de gases o filtro de mangas), mientras que los segundos pueden establecer concentraciones o flujo másico máximo en el efluente de descarga para ciertos contaminantes.

Este tipo de instrumento deja poca flexibilidad a las fuentes afectadas para el cumplimiento, generando mayores costos de reducción de emisiones. En el caso de Chile, se ha optado principalmente por establecer estándares de desempeño mediante normas de emisión, como la norma de emisión para motocicletas ${ }^{1}$, norma de emisión para incineración y coincineración ${ }^{2}$, norma de emisión para

${ }^{1}$ DS N. ${ }^{\circ} 104$ de 2000, Ministerio de Transportes y Telecomunicaciones.

2 De acuerdo con DS N. ${ }^{\circ} 45$ de 2007 del Ministerio Secretaría General de la Presidencia, esta norma aplica a toda instalación de incineración, construcción donde se realiza un tratamiento de destrucción térmica de sustancias o materias distintas a los combustibles tradicionales y bajo condiciones de operación controladas y de coincineración, como hornos rotatorios de cal e instalaciones forestales que utilizan como combustible sustancias o materiales distintos a los combustibles tradicionales y cuya finalidad principal sea la fabricación de productos. 
centrales termoeléctricas ${ }^{3}$, norma de emisión para calefactores ${ }^{4}$, entre otras.

No obstante los esfuerzos realizados, el problema de calidad del aire persiste y lograr las metas de reducción es (en el margen) cada vez más costoso, lo que obliga a buscar soluciones eficientes, como por ejemplo instrumentos económicos. El objetivo de este tipo de instrumentos es proveer incentivos a los agentes regulados para que disminuyan sus emisiones, dando flexibilidad en el modo en que se logra la reducción de las mismas. Los más relevantes corresponden a cargos por emisión, permisos transables, sistemas de depósito y reembolso, bonos por desempeño, subsidios y pago por pasivos (OECD 1999). La OCDE reconoce las ventajas de este tipo de herramientas, y en su "Evaluación de desempeño ambiental del país" (OECD 2005) recomienda introducir instrumentos económicos, como cargos por emisión y mejoras a los mecanismos de creación de mercado, mientras que el informe OCDE de $2013^{5}$ sugiere el uso de permisos transables para avanzar en la descontaminación de zonas urbanas.

El uso de instrumentos económicos en Chile es más bien limitado. La aplicación más desarrollada corresponde al esquema de cupos transables en la Región Metropolitana ${ }^{6}$, experiencia pionera en países en vías de desarrollo, que incorpora elementos de mercado al control de la contaminación y proporciona a las empresas flexibilidad para cumplir con sus metas de emisión (Sánchez et al. 2002, 267-287). Existe también experiencia en el uso de instrumentos económicos para el manejo sustentable de recursos naturales, donde destaca el "Código de aguas"7, que determina el establecimiento de derechos de aprovechamiento sobre el recurso hídrico y reglas de transacción de estos, y la "Ley general de pesca y acuicultura" 8 , que establece cuotas de pesca que pueden ser transadas entre los tenedores.

${ }^{3}$ DS N. ${ }^{\circ} 13$ de 2011, Ministerio del Medio Ambiente.

${ }^{4}$ DS N. ${ }^{\circ} 39$ de 2012, Ministerio del Medio Ambiente.

${ }^{5}$ Título original: OECD Economic Surveys: Chile 2013.

${ }^{6}$ DS N. ${ }^{\circ} 4$ de 1992, Ministerio de Salud, establece norma de emisión de material particulado a fuentes estacionarias puntuales y grupales.

${ }^{7}$ DFL N. ${ }^{\circ} 1.122$ de 1981, actualizado en 2010.

${ }^{8}$ Ley N. $^{\circ} 18.892$ de 1989 , actualizada en 1991 y modificada por la Ley N. ${ }^{\circ}$ 20.657 del año 2013 . 
Chile ha analizado por más de una década la factibilidad de implementar dichos mecanismos para la gestión de la contaminación. En julio de 2003, se ingresó al Congreso el "Proyecto de ley sobre bonos de descontaminación", sin llegar a aprobarse la idea de legislar. Siete años más tarde se retomó la discusión con un anuncio del Presidente Sebastián Piñera sobre la promoción de instrumentos de incentivo a la adopción de tecnologías limpias, como permisos transables e impuestos a las emisiones, anuncio que finalmente no se concretó ${ }^{10}$.

A su vez, durante el año 2012 se estudió la posibilidad de introducir un impuesto verde como instrumento económico para la gestión de residuos en el marco de la reforma tributaria. Este impuesto verde se orientaría a productos de corta vida útil y largo período de degradación ${ }^{11}$. Sin embargo, tras analizar los costos y beneficios de este instrumento, se llegó a la conclusión de que la forma más efectiva de aumentar las tasas de reciclaje era a través del instrumento económico conocido como "Responsabilidad extendida al productor"12, ampliamente utilizado en más de 45 países, el cual obliga a empresas fabricantes o importadoras de productos prioritarios a hacerse cargo de sus productos una vez terminada su vida útil.

Más tarde, en abril de 2014, la Presidenta Michelle Bachelet ingresó a la Cámara de Diputados un proyecto de ley de reforma tributaria ${ }^{13}$ que incluye la habilitación de cargos por emisiones de contaminantes locales (NOX, SOX, MP) y globales $\left(\mathrm{CO}_{2}\right)$. El impuesto se determinaría en función del costo social por unidad de contaminación. El proyecto de ley fue despachado el 20 de mayo al senado para su segundo trámite constitucional donde, como es bien conocido, se acordaron cerca de 200 modificaciones, aprobadas recientemente por amplia mayoría.

Como se observa, se han discutido varias propuestas de instrumentos económicos sin que ninguna — cuando se publica este artículo, a primeros días de septiembre de 2014 — se haya concretado. El presente

${ }^{9}$ Boletín 3290-12.

${ }^{10}$ Anuncio realizado durante el discurso del 21 de Mayo del año 2010.

${ }^{11}$ Información publicada en diario La Tercera, 11 de mayo de 2012, disponible en http://www.latercera.com/noticia/opinion/ideas-y-debates/2012/05/895459997-9-impuestos-verdes-desarrollo-sustentable.shtml

12 Información publicada en diario La Tercera, 27 de agosto de 2012, disponible en http://diario.latercera.com/2012/08/27/01/contenido/negocios/10117019-9-gobierno-elimina-impuestos-verdes-y-opta-por-proyecto-de-reciclaje.shtml

${ }^{13}$ Boletín 9290-05. 
trabajo describe las ventajas y desventajas de instrumentos económicos alternativos para la gestión de la calidad del aire, permisos de emisión transables e impuestos a las emisiones, en el contexto normativo chileno. Con esto se busca contribuir a la discusión pública en esta materia, resaltando los beneficios de avanzar desde esquemas de comando y control a instrumentos económicos, así como los principales elementos a considerar en su diseño.

El documento tiene la siguiente estructura: además de la introducción ya realizada, en la sección 2 se presentan consideraciones generales jurídicas y de eficiencia económica relativas a sistemas de permisos de emisión transables e impuestos; en la sección 3 se evalúan los costos y beneficios de ambos instrumentos y sus principales componentes, y finalmente, en la sección 4, se plantean algunas consideraciones finales.

Para ilustrar de mejor forma el análisis, se decidió enmarcarlo en un estudio de caso, simulando la implementación de estos mecanismos en Concepción metropolitano. Se seleccionó este caso particular ya que cuenta con una industria desarrollada, una alta población y es una de las pocas urbes en Chile (junto con el Gran Santiago) con las condiciones adecuadas para introducir estos esquemas. El Decreto 41/2006 del Ministerio Secretaría General de la Presidencia declaró las comunas de Concepción metropolitano como zona latente por $\mathrm{MP}_{10}$. Dicha declaración dio origen al requerimiento de implementar un Plan de Prevención Atmosférica (en adelante PPA), cuyo objetivo es prevenir que se alcance una situación de saturación en la zona. El presente análisis podría ser un aporte en la conformación de dicha regulación.

\section{SISTEMAS DE PERMISOS DE EMISIÓN TRANSABLES E IMPUESTOS}

Los instrumentos económicos más utilizados para la gestión de la calidad del aire son dos: los sistemas de permisos de emisión transables, conceptualizados como instrumentos de cantidad —o cap and trade-, que imponen un límite máximo de emisiones en un área geográfica, y los impuestos a las emisiones, conceptualizados también como instrumentos de precio. Los instrumentos de cantidad entregan certeza en la reducción de emisiones esperada, mientras que los instrumentos de precio entregan certeza en el costo del control de emisiones, llamado también costo de abatimiento. 
Ambos instrumentos incentivan a las empresas a reducir su contaminación, ya que, mientras menos emisiones generen, menos permisos necesitarán comprar o, bien, menos impuestos deberán pagar. De esta forma, las empresas reducirán emisiones mientras sus ahorros marginales sean iguales o menores al precio de los permisos o al nivel de impuesto, mientras puede ocurrir que empresas con altos costos relativos prefieran no reducir sus emisiones cuando les resulte más económico comprar permisos en el mercado o pagar el impuesto por emisión.

Las figuras A1 y A2, en la sección de Anexos, muestran la experiencia internacional en el uso de impuestos y sistemas de permisos de emisión transable para contaminantes locales respectivamente. Cabe la discusión sobre el tipo de instrumento económico preferible de implementar en Chile, teniendo en cuenta tanto factores teóricos de eficiencia como factores políticos y legislativos relevantes para una posible implementación.

\subsection{Consideraciones de eficiencia económica}

En ausencia de incertidumbre en costos de abatimiento y costos de transacción, la eficiencia de un sistema de permisos de emisión transables es equivalente a la de un sistema de impuestos (Goodkind et al. 2012; Hepburn 2006). No obstante, hay autores que exploran el desempeño de ambos instrumentos cuando esas condiciones no se cumplen.

Weitzman (1974) considera incertidumbre en los costos de reducción de emisiones y propone que la pertinencia de instrumentos de cantidad versus instrumentos de precio dependerá de las pendientes relativas de las funciones de costo y beneficio marginal, mostrando que los instrumentos de precio serán preferibles cuando la curva de beneficios marginales tiene pendiente menor que la curva de costos marginales. En caso contrario, los instrumentos de cantidad serían preferibles.

La línea argumental de Weitzman supone beneficios marginales decrecientes en el nivel de abatimiento, sin embargo, hay evidencia de que para $\mathrm{MP}_{2,5}$ los beneficios marginales aumentan al incrementarse el nivel de control (Pope et al. 2011). Este escenario es analizado por Goodkind et al. (2012), quienes muestran que en algunas situaciones una regulación de cantidad es equivalente a una de precios, pero en otras, una regulación de precio es preferida. 
La figura 1 grafica uno de los escenarios analizados por Goodkind et al. (2012). La figura 1a) muestra que para beneficios marginales crecientes e incertidumbre en los costos, la pérdida al fijar la reducción en $q^{*}$ (regulación de cantidad) es siempre mayor a la pérdida de fijar un impuesto $\mathrm{p}^{*}$ (regulación de precios). Análogamente, la figura 1b), esquematiza incertidumbre en los beneficios marginales, en que la fijación de un impuesto $\mathrm{p}^{*} \mathrm{o}$ de una reducción $\mathrm{q}^{*}$ conllevarían siempre al mismo resultado $\left(\mathrm{p}^{*}, \mathrm{q}^{*}\right)$, lo que implica la misma pérdida social $\mathrm{y}$, por lo tanto, hace a ambas regulaciones, de precio y de cantidad, equivalentes.

Como se puede observar para el caso de Concepción metropolitano, la figura 2a) muestra que, en el caso de incertidumbre en la curva de costo marginal, la pérdida social alcanzaría 1,5 millones de dólares. Al contrario, la pérdida asociada al fijar un impuesto es despreciable, debido a que la curva de beneficios marginales es prácticamente constante. La figura 2b) muestra que, en el caso de beneficios inciertos, la pérdida alcanzaría 5,4 millones de dólares por año en ambos casos.

Otros autores plantean que, pese a que los instrumentos de precio aparecen económicamente más eficientes (como en este caso particular), existen factores - como capacidad de fiscalización, información incompleta, poder de mercado, impactos sinérgicos y acumulativos, innovación tecnológica, la presencia de otros impuestos en la economía que distorsionen los precios finales de los insumos, entre otros- que afectarán la pendiente de las curvas de costos y beneficios marginales de abatimiento, y, por lo tanto, la recomendación final sobre el instrumento. Es por esto que la decisión de idoneidad debe tener en cuenta estas consideraciones y otras, de índole jurídica ${ }^{14}$.

\subsection{Consideraciones jurídicas}

De acuerdo con lo que dispone el artículo 47 de la Ley N. ${ }^{\circ} 19.300$, un plan de descontaminación puede utilizar como instrumento de carácter económico los impuestos a las emisiones. Sobre la base de esta norma, sería factible establecer, en el marco de un plan de descontaminación, impuestos específicos aplicables a las actividades productivas que se emplacen dentro del territorio sujeto al plan.

${ }^{14}$ La bibliografía en esta materia es extensa. Se consideró fuera del alcance de este estudio incluir una recopilación detallada de estos temas. Para mayor profundización, se sugiere revisar Montero (1999), Montero (2002) y Montero (2004). 
Figura 1. PÉRDIDA SOCIAL MEDIANTE UNA REGULACIÓN DE PRECIOS ( $\left.p^{*}\right)$ O MEDIANTE UNA REGULACIÓN DE CANTIDAD $\left(q^{*}\right)$, PARA DOS ESCENARIOS DE INCERTIDUMBRE

CMgg: Costo marginal. BMg: Beneficio marginal.

a) Incertidumbre en costos con beneficios marginales crecientes

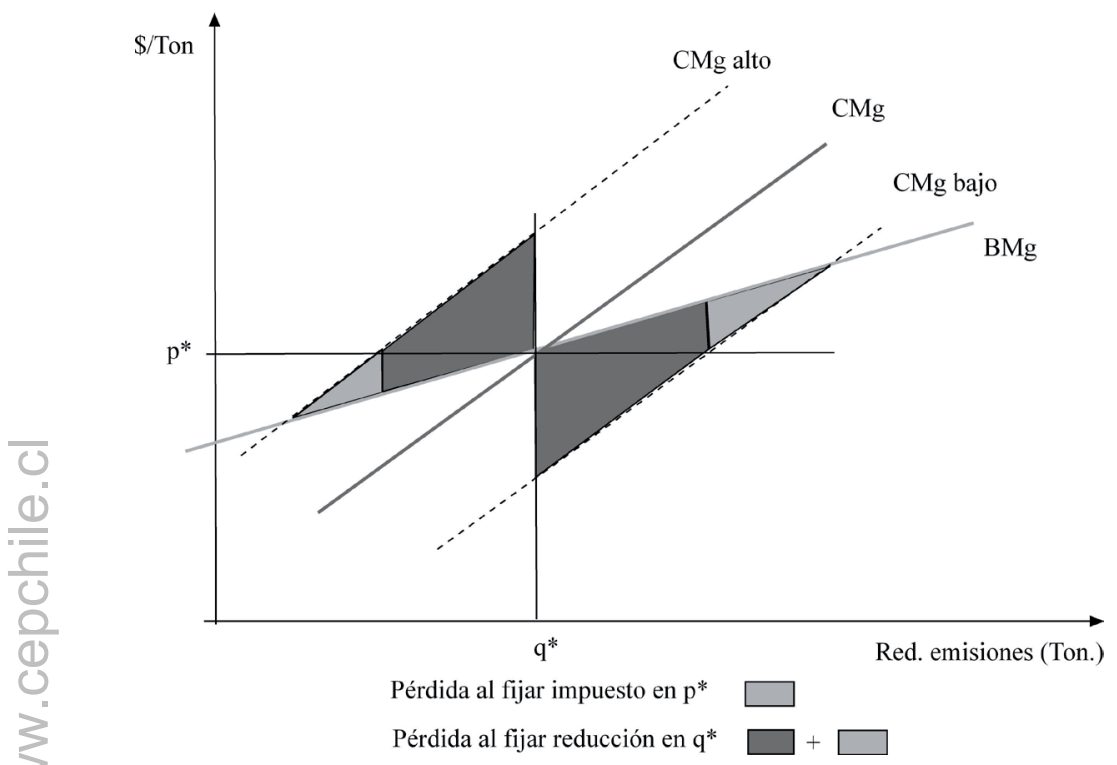

b) Incertidumbre en beneficios con beneficios marginales crecientes

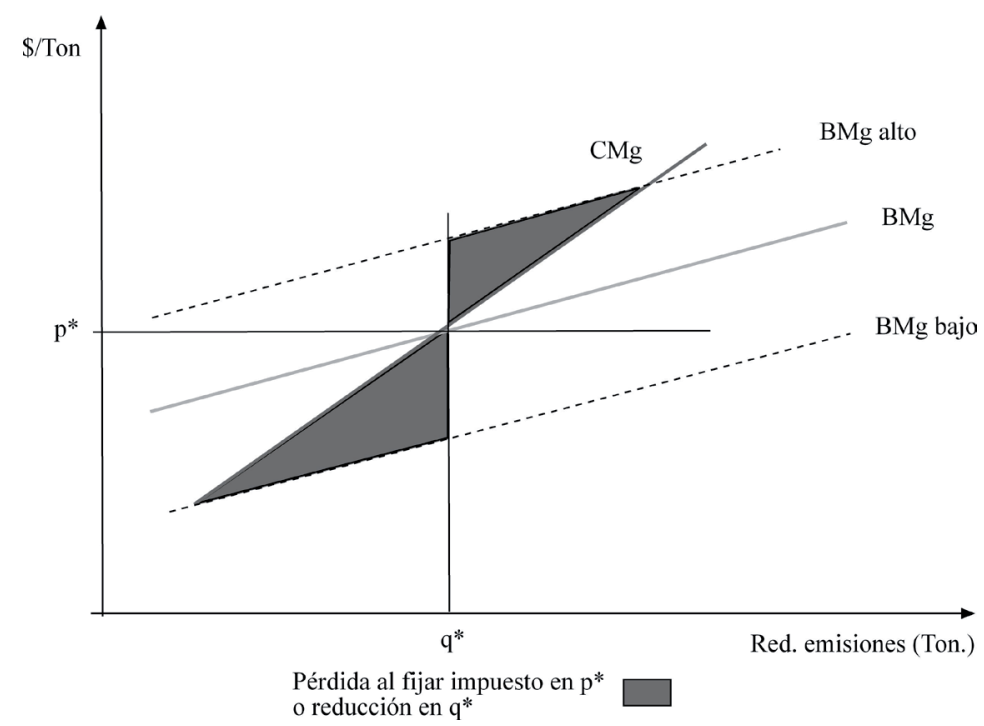

Fuente: Elaboración de los autores. 
Figura 2. PÉRDIDA SOCIAL EN UNA REGULACIÓN DE PRECIOS ( $\left.p^{*}\right)$ O EN UNA REGULACIÓN DE CANTIDAD $\left(q^{*}\right)$, PARA DOS ESCENARIOS

DE INCERTIDUMBRE, SIMULADO PARA CONCEPCIÓN METROPOLITANO

CMğ: Costo marginal. DMg: Daño marginal.

a) Incertidumbre en costos al regular el precio mediante impuestos $\left(p^{*}\right)$ o al regular en cantidad, al fijar la reducción de emisiones $\left(\mathrm{q}^{*}\right)$

$$
\left(\mathrm{p}^{*}, \mathrm{q}^{*}\right) \text { : Costo total de 12,4 MMUSD/año }
$$

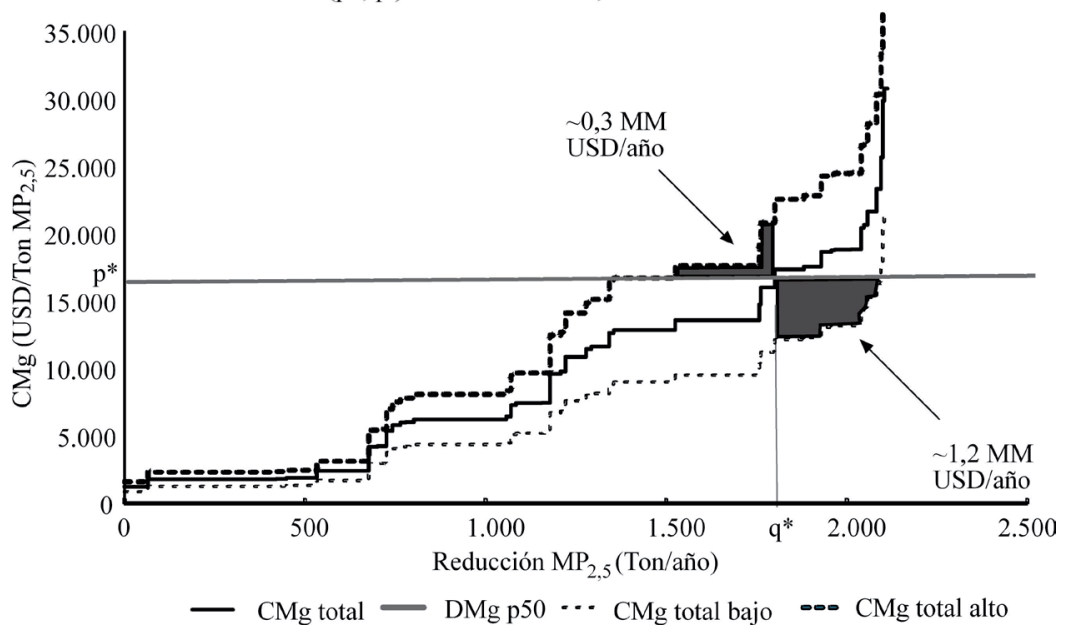

b) Incertidumbre en beneficios al regular el precio mediante impuestos $\left(p^{*}\right)$ o al regular en cantidad, al fijar la reducción de emisiones $\left(q^{*}\right)$

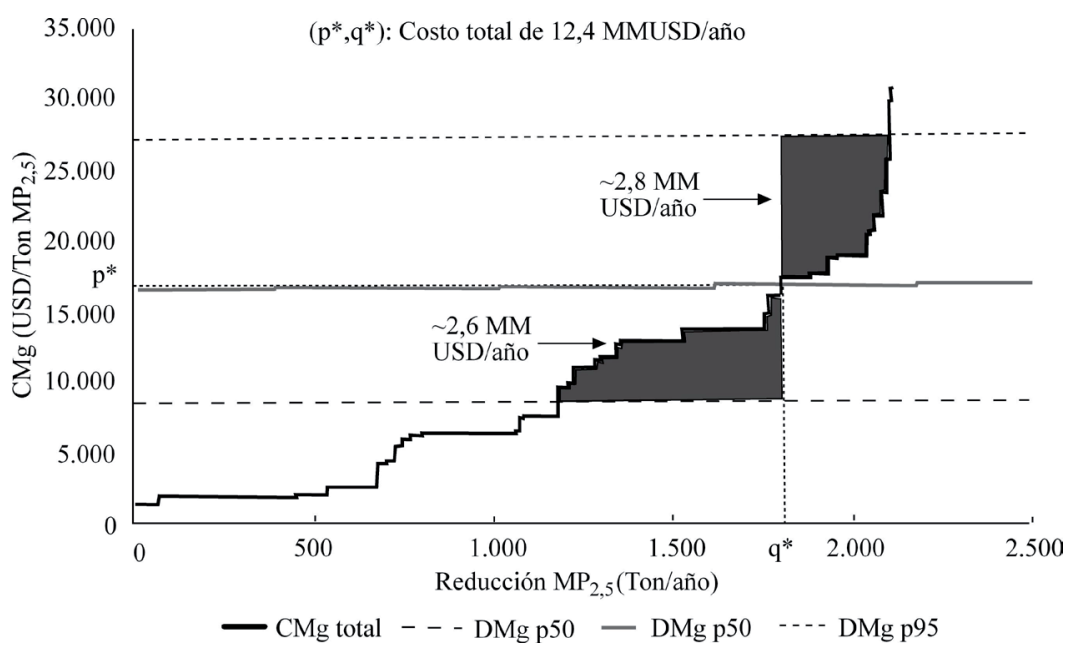

Fuente: Elaboración de los autores en base a Universidad de Concepción y Proterm (2011), Mideplan (2006), UdC - EULA (2010), USEPA (2010), INE (2012, 6) y Villena et al. (2007, 149).. 
Sin embargo, la aplicación de un impuesto se ve entorpecida, en la práctica, por ciertas limitaciones vinculadas a la regulación jurídica de los tributos en nuestro ordenamiento legal y constitucional. Se debe considerar que el establecimiento de impuestos depende del dictamen de una ley especial, que además es materia de iniciativa exclusiva del Presidente de la República, no siendo factible imponerlos mediante un plan de descontaminación, dada su naturaleza de instrumento infralegal.

Además, la regulación tributaria nacional se sujeta al principio de no afectación específica consagrado en la Constitución Política de la República ${ }^{15}$; esto es independientemente de la naturaleza del tributo o de los fines por los cuales fueron establecidos, ingresan a las arcas generales del Estado, sin que exista la posibilidad de destinarlos a un fin específico ${ }^{16}$. En consecuencia, podría cobrarse un impuesto por emitir, pero no podrían utilizarse directamente los fondos recaudados en la reducción de emisiones o la protección del medio ambiente. Es importante mencionar, sin embargo, que la eficiencia económica de un impuesto a la contaminación no requiere destinar los fondos recaudados para esos fines. Es más, podría ser contraproducente, al generar un problema de riesgo moral y alterar la eficiencia paretiana del sistema.

Por otra parte, al igual que en el caso de impuestos a las emisiones, los permisos de emisión transables son considerados como instrumentos de gestión ambiental (Bermúdez 2007, 33) factibles de utilizarse en los planes de prevención o de descontaminación ${ }^{17}$, pero en nuestra legislación los permisos de emisión no son regulados como tales dentro

${ }^{15}$ La Constitución Política de la República, Art. 19 N . ${ }^{\circ}$ 20, inciso tercero, dispone: "Los tributos que se recauden, cualquiera que sea su naturaleza, ingresarán al patrimonio de la Nación y no podrán estar afectos a un destino determinado".

${ }^{16}$ Sin perjuicio de las excepciones que la misma Constitución contempla en materia de defensa nacional $y$, en el caso de impuestos que graven actividades o bienes de clara identificación regional o local, los que podrán ser aplicados al financiamiento de obras de desarrollo por las autoridades regionales o comunales.

${ }^{17}$ El artículo 47 de la Ley N. ${ }^{\circ} 19.300$, sobre "Bases generales del medio ambiente", dispone: "Los planes de prevención o descontaminación podrán utilizar, según corresponda, los siguientes instrumentos de regulación o de carácter económico: a) Normas de emisión; b) Permisos de emisión transables; c) Impuestos a las emisiones o tarifas a los usuarios, en los que se considerará el costo ambiental implícito en la producción o uso de ciertos bienes o servicios, y d) Otros instrumentos de estímulo a acciones de mejoramiento y reparación ambientales". 
del título II de la Ley N. ${ }^{\circ} 19.300$, lo que deja su naturaleza y formas de asignación, división, transferencia, duración y demás características encomendados a una ley especial, de acuerdo a lo que prescribe el artículo 48. A casi veinte años de la promulgación de la normativa de bases generales del medio ambiente, dicha ley aún no ha sido dictada ${ }^{18}$.

Debe notarse que a pesar de que la misma Ley N. ${ }^{\circ} 19.300$ habla de "permisos de emisión transables", hay que decir que esta denominación no es la más adecuada a la hora de determinar la naturaleza jurídica de este instrumento, puesto que recurre a la categoría de derecho administrativo de "permiso", siendo discutible su carácter de tal. El permiso es "el acto administrativo por medio del cual se autoriza en forma exclusiva y excluyente un cierto uso de poca importancia jurídico-económicosocial sobre un bien de dominio público" (Montt 2002).

La concesión de dominio público, en tanto, es conceptualizada como "un título jurídico mediante el cual la administración otorga a un particular un derecho real, consistente en usar y aprovechar, de forma excluyente, bienes de dominio público en beneficio del particular y de la colectividad" (Montt 2002). Considerando lo anterior, mal podría considerarse que un permiso de emisión transable sea efectivamente un "permiso" o autorización. Por el contrario, los permisos de emisión transables propuestos por la literatura implican el otorgamiento, por parte del Estado, de un derecho privativo y excluyente para emitir una cierta cantidad de contaminantes en un determinado medio y, por tanto, se asemeja más a una figura concesional.

Sin embargo, considerando que la Ley N. ${ }^{0} 19.300$ encarga a una ley especial determinar la naturaleza jurídica del instrumento, adquiere especial relevancia darle una naturaleza que no encarezca los costos de transacción del sistema, como sí podría generarlos una figura concesional tradicional.

Junto con esto, y de acuerdo con el conocimiento teórico, es posible esbozar ciertos lineamientos acerca de la naturaleza del permiso de emisión transable que limitan su aplicación. El permiso de emisión

${ }^{18}$ La Ley N. ${ }^{\circ} 19.300$ deja abierto el medio específico sobre el cual pueden operar los permisos de emisión transables (sea éste el acuático, atmosférico o el suelo) y la determinación de aspectos fundamentales como los contaminantes objeto de transacción, la clase de personas o actividades que podrán participar en el sistema y el ámbito de aplicación territorial que pueda corresponder a un sistema. 
transable analizado como un acto administrativo ${ }^{19}$ representa un acto decisorio, por cuanto crea, modifica o extingue una situación jurídica determinada; un acto favorable, puesto que la situación jurídica que se crea reviste un carácter activo; y un acto constitutivo, ya que crea una situación ex novo. Esto genera consecuencias como, por ejemplo, eventuales indemnizaciones compensatorias para los tenedores de permisos de emisión por parte del Estado ante la revocación del acto.

Desde el punto de vista de economía política, podría concebirse inicialmente que un esquema de permisos transables — considerando el resguardo que éste genera en el cumplimiento de metas ambientales - sería de mayor aceptación que el uso de impuestos. No obstante, la práctica ha demostrado lo contrario. El proyecto de ley de "Bonos de descontaminación" no ha avanzado en su tramitación desde hace más de una década y la aprobación de un sistema de impuestos a las emisiones propuesto como parte de la reforma tributaria del año en curso avanza consistentemente en el Congreso Nacional.

Se puede argumentar que, en el caso de un bien público como la calidad del aire (no rival y no excluible) ${ }^{20}$, la ciudadanía no se muestra favorable a la generación de mercados para su gestión ${ }^{21}$. Más aún, el régimen jurídico que administra los bienes de dominio público presenta las características de inalienabilidad e incomerciabilidad, con el propósito de asegurar el destino de uso común propio de este tipo de bienes, lo que implica que no son susceptibles de dominio ni apropiación según se establece en el Código Civil y la Constitución Política de la República. De esta forma, no pueden ser objeto de actos jurídicos regidos por el derecho privado de forma que puedan atentar contra tal uso público.

${ }^{19} \mathrm{El}$ acto administrativo se define en el artículo $3^{\circ}$ de la Ley N. ${ }^{\circ} 19.880$ - "Bases de los procedimientos que rigen los actos de la administración del Estado"- como las decisiones formales que emitan los órganos de la administración del Estado en las cuales se contienen declaraciones de voluntad, realizadas en ejercicio de una potestad pública.

${ }^{20}$ Un bien puede definirse como "no rival" cuando el consumo de una unidad más del bien no afecta el consumo de los demás. En tanto, un bien es "no excluible" cuando no es posible racionar su uso una vez que el bien ha sido producido o cuando es difícil excluir a otro consumidor (el costo marginal de excluir es muy alto). Ver Kolstad (2011).

${ }^{21}$ Este es el caso de la discusión pública en materia de educación escolar, por ejemplo, donde hoy se discute la conveniencia de su provisión a través de mercados privados. 
Sin embargo, no se ve impedimento para que estos bienes puedan ser objeto de lo que se denomina un comercio de índole público o administrativo, gobernado por el principio de la precariedad, al contrario de lo que ocurre en las relaciones jurídicas civiles, permanentes y definitivas por regla general. Incluso, quienes niegan todo derecho de propiedad sobre los bienes nacionales de uso público aceptan la realización de determinados actos que implican efectuar un comercio sobre ellos, en especial respecto de su uso y goce de aprovechamiento de sus frutos o accesorios (Celaya 2002). La inalienabilidad del dominio público no importa ninguna restricción o limitación a un posible tráfico jurídico de derecho público, pues éste lo mantiene siempre bajo una titularidad jurídica pública y no menoscaba la afectación de los bienes dominicales (Montt 2002).

\section{IMPUESTOS Y PERMISOS: PRINCIPALES ELEMENTOS DE DISEÑO}

De acuerdo con lo que hemos visto, la teoría muestra ventajas y desventajas de cada sistema. En la presente sección se describen los principales componentes de ambos mecanismos y se exponen sus diferencias. Para ilustrar la discusión, se describe cómo estos elementos aplicarían en el caso de Concepción metropolitano y se simula su desempeño.

Para la implementación de este tipo de regulaciones se requiere que su diseño contemple, entre otros aspectos, la fijación de una meta de reducción de emisiones, la determinación de su cobertura, los requerimientos de monitoreo y de reporte de emisiones, las reglas que regulen su operación y las disposiciones para su fiscalización y cumplimiento. En las siguientes subsecciones se analizan estos elementos. Ellos fueron seleccionados según el criterio de los autores. No se encuentra dentro del alcance de este documento hacer un análisis exhaustivo de cada uno de los elementos de este tipo de esquemas (para mayor detalle ver Tietenberg 2006 y Kolstad 2011).

\subsection{Metas de reducción de emisiones}

En el caso de un impuesto, las empresas reducirán sus emisiones mientras el costo marginal de abatimiento sea igual o menor al nivel del impuesto, por lo que la meta de reducción de emisiones dependerá 
-implícitamente - de la tarifa establecida. Para determinar esta tarifa una alternativa es definir el impuesto como el costo social equivalente al impacto (o daño) marginal por aumentos en la concentración de material particulado $(\mathrm{MP})^{22}$, principalmente debido a sus efectos en salud. La metodología utilizada corresponde a la propuesta por USEPA (1991), conocida como función de impacto, y adaptada por Ministerio de Medio Ambiente (MMA 2011). Propone la siguiente expresión:

Impuesto $\left[\frac{U S D}{T o n}\right]=\sum_{i j} \operatorname{Casos}$ Base $\left(P_{j o b} \cdot T I_{i j}\right) \cdot \beta_{i j} \cdot V U_{i} \cdot F E C$

Donde,

$P o b_{j}$ : Población expuesta del grupo de edad $j$

$T I_{i j}$ : Tasa de incidencia en casos cada 100 mil habitantes del evento $i$ en el grupo de edad $j$

$\beta_{i j}$ : Coeficiente de riesgo relativo (\%) evento $i$ en grupo edad $j$ por $\mu \mathrm{g} / \mathrm{m}^{3} \mathrm{MP}_{2,5}$.

$V U_{i}$ : Valor unitario en dólares por evento $i$

$F E C$ : Factor emisión-concentración en $\mu \mathrm{g} / \mathrm{m}^{3}$ de $\mathrm{MP}_{2,5}$ por ton de $\mathrm{MP}_{10}$.

En el caso de Concepción metropolitano, el impuesto correspondería a 17 mil dólares por tonelada de $\mathrm{MP}_{2,5}$ emitida al medio ambiente, asumiendo que el valor unitario para eventos de mortalidad prematura (valor de la vida estadística o VVE) corresponde a una distribución triangular con parámetros (mínimo, moda, máximo) igual a 4.953, 10.845, 15.454 UF respectivamente, un coeficiente de riesgo de 9.3 por ciento por cada $10 \mu \mathrm{g} / \mathrm{m}^{3}$ de $\mathrm{MP}_{2,5}$ en promedio anual y como población expuesta el total en las comunas declaradas como latentes por $\mathrm{MP}_{10}$.

Cabe destacar que el valor de la tarifa en este caso dependerá de los supuestos considerados. Por ejemplo, si el VVE utilizado fuera 13.042 UF (MDS 2014), el impuesto sería alrededor de 20.500 USD/ ton; mientras que si el VVE fuera 26.500 UF (OCDE 2012b), el impuesto alcanzaría aproximadamente 41.200 USD/ton para las comunas de Concepción metropolitano.

${ }^{22}$ Las reducciones de MP son llevadas a su nivel equivalente en términos de $\mathrm{MP}_{2,5}$, para el cual existe mayor incidencia de impactos en mortalidad prematura. 
Como contrapartida, en el caso de un sistema de permisos de emisión transables, la fijación de la meta corresponde al límite máximo de emisiones (cap). Éste debería considerar los costos y beneficios ${ }^{23}$ de su cumplimiento, de modo de maximizar el bienestar social, igualando beneficios marginales a costos marginales. Considerando la eficiencia económica del sistema, las metas de reducción por sector deberían ser acordes con el principio de equimarginalidad de costos, esto es, que el costo de la última unidad de emisión reducida sea el mismo entre los distintos sectores participantes (Kolstad 2011).

En la figura 3 se presentan los costos marginales para los dos principales sectores a regular en el "Plan de prevención atmosférica de Concepción metropolitano" y los impactos marginales (DMg) asociados a la reducción de emisiones de $\mathrm{MP}_{2,5}$. La disminución óptima para el sector industrial correspondería a aproximadamente 1.800 toneladas de $\mathrm{MP}_{2,5}$ por año, muy por encima de las 945 toneladas que se alcanzarían con las medidas establecidas en el anteproyecto del plan de prevención para esta zona. Como se indicó anteriormente, en ausencia de incertidumbre ambos tipos de regulación entregarían resultados equivalentes.

\subsection{Cobertura del sistema}

Teóricamente, podría considerarse como óptimo incluir la mayor cantidad de sectores y fuentes con el objetivo de obtener la eficiencia económica más alta posible. No obstante, en la práctica, la inclusión de gran cantidad de fuentes puede significar una carga administrativa enorme. Así, para determinar la cobertura sectorial idónea del sistema se debe considerar cuál es la participación de cada sector en el total de emisiones, información que se obtiene a partir del inventario de emisiones de la zona, y de los costos de su inclusión.

En Concepción metropolitano, los mayores aportes a las emisiones de material particulado fino se registran en el sector residencial (consumo de leña, 77 por ciento) e industrial ( 21 por ciento), mientras que el sector transportes (1,6 por ciento) y agrícola (quemas, 0,3 por ciento) aportan una proporción mucho menor de este contaminante (MMA 2013). Si bien el sector residencial es el mayor aportante de emisiones en Concepción

${ }^{23}$ Los costos de abatimiento del sector industrial se calculan en base a USEPA (2010), utilizando la ecuación 8 para material particulado, en función del gasto volumétrico por chimenea. 
Figura 3. COSTOS MARGINALES PARA EL SECTOR INDUSTRIAL Y RESIDENCIAL EN EL CONCEPCIÓN METROPOLITANO

CMģ: Costo marginal. DMgg: Daño marginal.

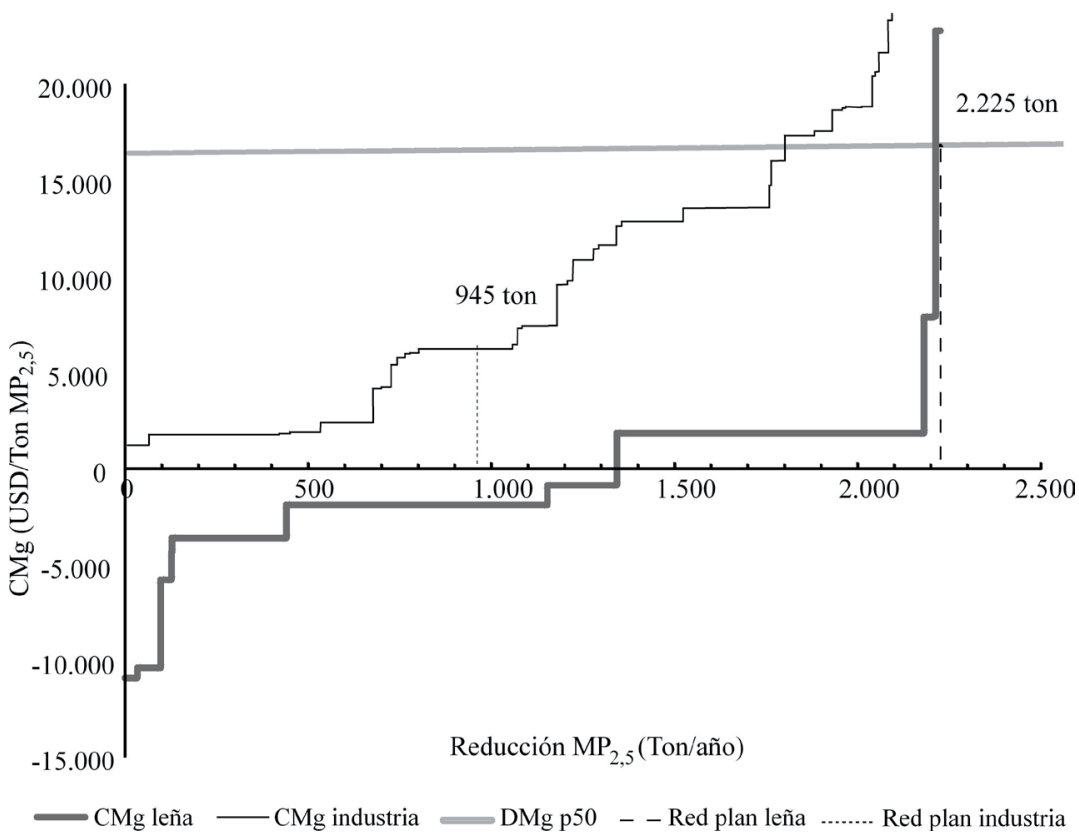

Fuente: Elaboración de los autores en base a UdC-Proterm (2011, 448-461), Mideplan (2006), UdC - EULA (2010), USEPA (2010), INE (2012,6) y Villena et al. (2007, 149).

metropolitano, también es un sector compuesto por gran cantidad de pequeñas fuentes (136 mil en 2013), lo que puede complejizar y encarecer su inclusión. En el sector industrial, por su parte, 90 fuentes pertenecientes a 43 empresas concentran el 90 por ciento de las emisiones, lo que haría más factible su control. Adicionalmente, este sector ya cuenta con la obligación de reportar anualmente información relevante para la estimación de sus emisiones de acuerdo a lo requerido por el Decreto N. ${ }^{\circ} 138 / 2005$ del Ministerio de Salud ${ }^{24}$, lo que facilitaría su vigilancia.

${ }^{24}$ El control del emisor directo obliga a quienes emiten. Por su parte, el enfoque de emisor potencial obliga a quienes se comportan como intermediarios (e.g. los que extraen, procesan o distribuyen combustible), previo a la generación de emisiones, y se utiliza principalmente cuando existe gran cantidad de pequeños emisores difíciles de fiscalizar. Este tipo de enfoque también se conoce como aguas arriba o upstream. 


\subsection{Monitoreo, reporte y verificación}

Para la implementación exitosa de un sistema cap and trade, o de impuesto a las emisiones, es fundamental contar con información completa, precisa, oportuna y veraz; por esto, tanto el monitoreo como el reporte y la verificación (MRV) son elementos centrales a la hora de diseñar un sistema de permisos de emisión transables (SPET) o un sistema de impuestos.

En Chile, el D.S. 138/2005 del Ministerio de Salud establece la obligación a fuentes fijas de entregar información necesaria para estimar sus emisiones ${ }^{25}$. Por su parte, el Ministerio del Medio Ambiente (MMA) administra el Registro de Emisiones y Transferencia de Contaminantes $(\text { RETC })^{26}$, que permite registrar, sistematizar y estimar, por fuente o agrupación de fuentes de un mismo establecimiento, la naturaleza, caudal y concentración de emisiones de contaminantes que sean objeto de una norma de emisión ${ }^{27}$.

No obstante, la obligatoriedad del D.S. 138/2005 no garantiza el cumplimiento de estándares de calidad de la información reportada, necesarios para una adecuada gestión ambiental. A nivel agregado, se han identificado problemas de completitud y falta de precisión, evidenciando la necesidad de contar con mejores elementos de verificación y fiscalización. Cabe destacar el avance en esta línea que implica la obligación establecida en el D.S. 1/2013 del MMA, que establece un sistema de ventanilla única asociada al RETC mediante un reporte electrónico estandarizado.

Dada la importancia de los reportes para la integridad de un sistema, la verificación de éstos por auditores externos o terceras partes autorizadas juega un rol determinante en la implementación de un adecuado monitoreo. En Estados Unidos, las fuentes que participan de los programas de cap and trade vigentes, con el fin de promover la

${ }^{25}$ Las fuentes fijas que reportan información para la estimación de emisiones son: calderas generadoras de vapor o agua caliente, producción de celulosa, fundiciones primarias y secundarias, centrales termoeléctricas, producción de cemento, cal o yeso, producción de vidrio, producción de cerámica, siderurgia, petroquímica, asfaltos y equipos electrógenos.

${ }^{26}$ Establecido mediante la Ley N. ${ }^{\circ} 19.300$ en su artículo 70 letra p).

${ }^{27}$ En algunos casos y formas que establezca el reglamento se registrarán y estimarán emisiones que no sean materia de una norma de emisión vigente. 
precisión de la información reportada, reportan sus propias emisiones o pagan a privados para hacerlo, con firma electrónica y un certificado del representante de la fuente, quien declara, bajo pena de multa o prisión, que los datos reportados son válidos y completos, lo que produce un incentivo directo sobre el responsable del reporte (Forte et al. 2006). Otro tipo de incentivo es el aplicado por el Sistema de Transacción de Emisiones de la Unión Europea, en el que se impide a la fuente efectuar transferencias mientras no se considere satisfactorio su informe verificado (Parlamento Europeo y del Consejo 2003). El D.S. 1/2013 del MMA sigue lo propuesto por Forte et al. (2006), se incluyen responsabilidades individuales en los reportes y establece una declaración jurada por parte del responsable del establecimiento, lo que incentivaría a reportar información fidedigna.

Estos sistemas de monitoreo pueden ser complementados con medidas más exigentes para emisores mayores, como el monitoreo continuo en chimenea, establecido en el marco del D.S. 13/2011 del MMA para el parque termoeléctrico y en el D.S. 66/2009 del Ministerio Secretaria General de la Presidencia para los mayores emisores en la Región Metropolitana. En estos casos, la magnitud de las emisiones justifica el costo de monitoreo continuo en chimenea.

\subsection{Asignación de permisos de emisión}

La asignación inicial de los permisos es uno de los aspectos más controversiales en el diseño de un sistema de permisos de emisión transables. Aunque en teoría no debería tener repercusiones en la eficiencia del sistema, en la práctica tiene gran importancia en la distribución de costos entre las fuentes y en la equidad de su resultado (Hatcher et al. 2000).

Entre las principales opciones para asignar los permisos de emisión transables destacan la distribución a título gratuito (según algún criterio previamente establecido) y la subasta de permisos, donde el primer mecanismo suele ser el más utilizado hasta la fecha. Los sistemas implementados, tanto en Estados Unidos -U.S. $\mathrm{SO}_{2}$ Allowance Trading Program y el Reclaim Program — como en la Unión Europea —EU ETShan comenzado con asignación gratuita, considerando para ello el nivel de actividad de las fuentes y sus emisiones históricas. 
Sin embargo, la distribución de permisos mediante subasta es un mecanismo ampliamente apoyado por la literatura económica como la opción más eficiente, al asegurar que el ítem subastado lo obtendrá quien más lo valore (Tietenberg 2006) y al evitar, a su vez, sesgos en la distribución final de permisos hacia quien tuvo la propiedad inicial (Saavedra y Willington 2012). Otra ventaja de las subastas es que proveen una señal de precios en el mercado, evitan condiciones desfavorables para nuevos entrantes y la recaudación asociada puede ser usada para compensar gastos administrativos o para distribuirse entre grupos afectados. Algunos aspectos relevantes a considerar en la subasta son su frecuencia, la vigencia de los permisos a subastar y los procedimientos de licitación (USEPA 2003).

En el caso del EU ETS, en la segunda fase se comenzó a aplicar la modalidad de subasta como mecanismo de distribución de permisos, con lo que se aumentó la eficiencia, la transparencia y la simplicidad del ETS (Comisión Europea 2009). El 50 por ciento de los ingresos se utilizan para reducir emisiones de gases de efecto invernadero en otros sectores; desarrollar energías renovables, tecnologías de captura de carbono y acciones de eficiencia energética, y cubrir gastos administrativos del sistema (Parlamento Europeo y del Consejo 2003).

Con respecto a las condiciones para fuentes nuevas en un sistema, éstas podrían recibir asignación gratuita de acuerdo con criterios equivalentes a los de fuentes existentes (reservando un porcentaje del cap) o bien adquirir permisos en el mercado. En la experiencia del U.S. SO2 Allowance Trading Program y del Reclaim Program, las fuentes nuevas deben comprar permisos para cumplir con sus obligaciones (USEPA 2003), mientras que en el EU ETS se consideró una reserva que permitiera asignarles gratuitamente permisos de emisión, con excepción de aquellas fuentes generadoras de electricidad (Parlamento Europeo y del Consejo 2003). Siguiendo esta experiencia, en el caso de estudio en Concepción metropolitano sería recomendable comenzar con una etapa de asignación gratuita, que permita a las fuentes cubiertas diseñar estrategias para adaptarse al nuevo escenario, y seguir con una segunda fase que contemple la distribución de una fracción de permisos a través de una subasta, aumentándola gradualmente hasta alcanzar el total de permisos. 


\subsection{Transacción de permisos de emisión}

Respecto de la transacción de permisos, es necesario establecer las reglas que regirán el sistema. Éstas deberían ser neutrales, en términos de no favorecer a grupos o individuos en el mercado, y deben promover bajos costos de transacción entre los participantes (USEPA 2003). El impacto potencial de los costos de transacción en el mercado de permisos está documentado en profundidad en el estudio de Stavins (1995), en el que se demuestra que la presencia de éstos reduce el volumen de permisos transados e induce, además, a que el equilibrio de mercado dependa de la distribución inicial, alejándose en general del escenario de mayor costo-efectividad.

Por otra parte, contar con una plataforma que facilite las transacciones es relevante en la reducción de dichos costos. Las transacciones se podrían realizar de manera bilateral a través de un sistema over the counter (OTC) o de manera multilateral a través de una bolsa. Las transacciones OTC se caracterizan por su flexibilidad en términos de diseño de contrato, mientras que las transacciones vía bolsa se encuentran bastante estandarizadas y cuentan con altos niveles de seguridad. Asimismo, los intermediarios, inversionistas y otros creadores de mercado pueden jugar un rol fundamental en facilitar las transacciones.

\subsection{Compensaciones}

La compensación de emisiones, también conocida como offsets, es utilizada en muchos sistemas de transacción de emisiones con el fin de facilitar el cumplimiento de las fuentes a menor costo. También podría ser considerada en un sistema de impuestos mediante la conformación de un crédito tributario en estos casos. Esta alternativa permite reducir emisiones en fuentes que se encuentran fuera del alcance del sistema, las que deben ser certificadas de acuerdo a estándares que garanticen su validez. Debe tenerse especial cuidado en asegurar que las compensaciones impliquen reducciones adicionales de contaminantes. En ocasiones, las compensaciones que se ofrecen corresponden a acciones que se hubiesen realizado igualmente, es decir, no existiría una mejora ambiental con respecto al statu quo (Montero 1999). 


\subsection{Cumplimiento y sanciones}

El sector regulado deberá pagar los impuestos requeridos obtener los permisos necesarios para respaldar sus emisiones dentro de una fecha límite ${ }^{28}$. Las fuentes deberán contabilizar sus emisiones, validarlas y reportarlas a la autoridad. Posteriormente, la autoridad deberá determinar el cumplimiento efectivo e identificar potenciales infracciones.

En el caso de infracciones, el diseño de sanciones disuasivas es un elemento determinante: que éstas sean suficientemente severas es un requisito fundamental para proveer al sector regulado de incentivos para el cumplimiento. En cuanto al monto de la sanción, éste debería ser sustancialmente mayor al costo marginal de abatimiento esperado (USEPA 2003). Asimismo, otros autores señalan la necesidad de que las sanciones sean conocidas y proporcionales a lo que se exceda (Kolstad 2011).

De acuerdo a la directiva marco europea ${ }^{29}$, las sanciones deben ser eficaces. Si estas medidas coercitivas no logran garantizar el cumplimiento del sistema, se podrá tomar acciones adicionales como prohibir la operación del infractor (Parlamento Europeo y del Consejo 2003). La Agencia de Protección Ambiental (EPA) de Estados Unidos sugiere que las sanciones sean aplicadas automáticamente en caso de incumplimiento. Sin embargo, en el caso de Chile, características propias de la legislación podrían limitar la aplicación de sanciones automáticas ${ }^{30}$.

En Chile, la Superintendencia del Medio Ambiente es el organismo encargado de fiscalizar infracciones a instrumentos de gestión ambiental. De acuerdo con su ley orgánica, infracciones gravísimas pueden implicar multas de hasta diez mil unidades tributarias anuales, y eventualmente la paralización temporal o permanente de la operación. Sin embargo, estas sanciones pueden ser insuficientes para garantizar el cumplimiento de estos sistemas. En el caso de impuestos, la fiscalización se vería fortalecida por el supervigilancia ejercida por el Servicio de Impuestos Internos. Las penalidades correspondientes, en este caso,

${ }^{28}$ Un periodo apropiado podría ser de 60 días, de manera que las fuentes puedan hacer sus últimas transacciones.

${ }^{29}$ Indicado en el artículo 16 de la Directiva 2003/87/CE del Parlamento Europeo y del Consejo.

${ }^{30}$ En vista del derecho de toda persona a defensa jurídica. Ver D.S. N. ${ }^{\circ} 100$ de 2005, Ministerio Secretaría General de la Presidencia, "Fija texto refundido, coordinado y sistematizado de la Constitución Política de la República de Chile". 
son las tipificadas en el artículo 97 del Código Tributario, respecto de infracciones como el retardo u omisión en la presentación de declaraciones o informes que constituyan la base inmediata para la determinación de un impuesto, o declaraciones maliciosamente incompletas o falsas. Esta última infracción, por ejemplo, involucra multas del 50 al 300 por ciento del valor del tributo eludido y sanciones penales correspondientes a presidio menor en sus grado medio a máximo para quienes resulten responsables.

En cualquier caso, se debe velar porque la amenaza de sanciones proporcionales al incumplimiento sea creíble (Chávez y Stranlund 2000). Para esto, la probabilidad de fiscalización debe ser alta. Mecanismos como el monitoreo continuo de emisiones permitirían aumentar el valor esperado de la sanción en presencia de incumplimientos.

\subsection{Procedimientos administrativos}

De acuerdo con el Ministerio de Hacienda y Ministerio del Medio Ambiente (2014) desde la promulgación de la Ley N. ${ }^{\circ} 19.300$ el país mantiene una larga tradición de buenas prácticas en materia regulatoria. Siguiendo las recomendaciones de la OCDE (2012a), se realiza sistemáticamente la consulta pública y evaluación del impacto económico y social de las regulaciones ambientales (AGIES). En el caso de la implementación de instrumentos económicos, se debe preservar este tipo de controles administrativos, lo que estaría asegurado en el marco de planes de prevención o descontaminación, de acuerdo con lo exigido por el D.S. 39/2012 del Ministerio del Medio Ambiente.

En particular, el AGIES debería comparar la eficiencia del uso de instrumentos económicos con respecto a regulaciones de comando y control alternativo. Esto permitiría destacar las potenciales ganancias de preferir instrumentos de precios o de cantidad.

Por ejemplo, para el caso de estudio de Concepción metropolitano, se estimaron los costos de cumplimiento de las metas del Plan de Descontaminación Atmosférica referido. Se evaluaron tres escenarios: ${ }^{31}$ i) la implementación del Plan concebido, que considera

${ }^{31}$ La modelación de escenarios no considera costos de transacción, costos de administración de un sistema ni existencia de asimetrías de información. 
cierta flexibilidad para complejos industriales ${ }^{32}$ al permitir reducir sus emisiones en las fuentes que resulten menos costosas dentro de cada establecimiento; ii) el escenario comando y control, que considera la aplicación de una norma de emisión sin permitir flexibilidad dentro de cada complejo industrial, y iii) el escenario con un sistema de permisos de emisión transables (SPET), equivalente al del uso de un impuesto.

Los resultados se presentan en la figura 4. Como indica la teoría económica, mientras mayor flexibilidad se otorgue a las empresas para abatir, menores serán los costos de cumplimiento. Si se fijara un nivel de abatimiento de 945 toneladas de $\mathrm{MP}_{2,5}$ (meta del anteproyecto de PPA), se tendría que el escenario Plan es un 28 ciento más económico que el escenario de comando y control, mientras que el escenario SPET sería 61 por ciento más económico que el de comando y control. Como se aprecia, la implementación de instrumentos económicos en Concepción metropolitano podría generar un ahorro considerable en costos de cumplimiento para alcanzar la meta de emisiones establecida en el anteproyecto $^{33}$.

Ahora bien, la compensación de emisiones podría jugar un rol relevante. Considerando una reducción de 945 toneladas del $\mathrm{MP}_{2,5}$ para el sector industrial, equivalente a implementar las medidas del anteproyecto, incluir compensaciones podría reducir costos en 41 por ciento respecto del escenario SPET, 68 por ciento con respecto al escenario Plan y 77 por ciento respecto del escenario comando y control.

\section{CONSIDERACIONES FINALES}

La mala calidad del aire en el país sugiere que deben tomarse acciones decididas para revertir esta condición y limitar la exposición de la población a concentraciones por sobre la normativa vigente. A pesar de la implementación de medidas de comando y control - principalmente normas de emisión-, lograr las metas de reducción es cada vez más costoso. Esto obliga a buscar soluciones eficientes económicamen-

${ }^{32}$ Se consideran complejos industriales por material particulado (MP) aquellos con emisiones iguales o superiores a 100 ton MP/año. Complejos industriales por $\mathrm{SO}_{2}$ son aquellos con emisiones superiores o iguales a 250 ton $\mathrm{SO}_{2} /$ año.

${ }_{33}$ Anteproyecto de "Plan de prevención atmosférica para Concepción metropolitano". 
Figura 4. COSTOS MEDIOS (CMe) DE REDUCCIÓN DE EMISIONES DE MP ${ }_{2,5}$ DEL SECTOR INDUSTRIAL

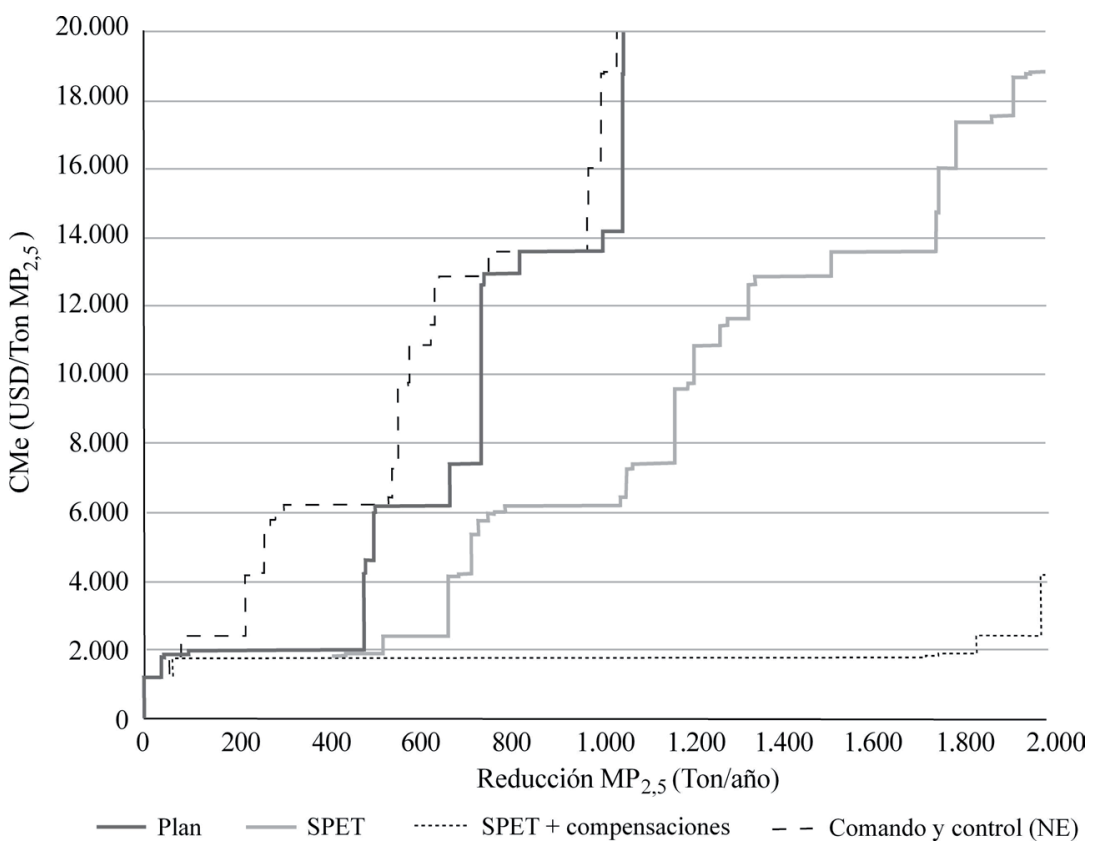

Fuente: Elaboración de los autores en base a UdC-Proterm (2011, 448-461) y USEPA (2010).

te, como los instrumentos económicos. De acuerdo con la teoría, en ausencia de costos de transacción e incertidumbre, un sistema de permisos de emisión transables (SPET) es equivalente, en términos de eficiencia económica, a un impuesto por unidad emitida. No obstante, hay aspectos que inclinan las preferencias por uno u otro de estos instrumentos.

En el caso de la contaminación del aire, mientras que una regulación de cantidad (permisos de emisión) nunca será estrictamente más eficiente que una regulación de precio (o impuestos), los permisos de emisión son el único instrumento que en teoría aseguraría el cumplimiento de la meta ambiental, aspecto fundamental para el resguardo del derecho constitucional de vivir en un medio ambiente libre de contaminación. No obstante, impuestos a las emisiones podrían ser más efectivos en incentivar el cumplimiento, al sumar las potestades del Servicio de Impuestos Internos a la fiscalización realizada por la Superintenden- 
cia del Medio Ambiente. Esto reforzaría la integridad de la regulación, lo que podría redundar en un mayor nivel de protección.

Por otra parte, la operación de un sistema de permisos de emisión transables requiere regular la asignación inicial de permisos y su transacción, lo que complejiza significativamente su operación en comparación con un sistema de impuestos. Sin embargo, los permisos, por vía reglamentaria, facilitan la inclusión de consideraciones de equidad en el cumplimiento de la regulación, al ser factible diferenciar el nivel de exigencia para ciertas industrias o grupos socioeconómicos. Un esquema de impuestos a las emisiones vería limitada sus posibilidades de realizar este tipo de distribución de la carga de la regulación, considerando que el artículo 19 N. ${ }^{\circ} 20$ de la Constitución establece que cualquier progresión en la repartición de tributos es materia legal. Empero, los nuevos recursos ingresados a las arcas fiscales permitirían su distribución focalizada, siendo discutible que un instrumento de gestión ambiental, como un sistema de permisos transables, sea la manera más eficiente de establecer consideraciones económicas y sociales.

La implementación de mecanismos como los descritos requiere, sin duda, de la voluntad política de la autoridad. Sin perjuicio de la decisión, se recomienda promover acciones tempranas a favor del fortalecimiento institucional ambiental en materia de competencias y herramientas para la gestión futura de instrumentos económicos. Esto involucra el robustecimiento de los sistemas de monitoreo continuo, reporte y verificación; la determinación de competencias certificadoras y fiscalizadoras; el establecimiento de programas de fiscalización, multas y sanciones atingentes, $\mathrm{y}$, ciertamente, la coordinación entre instituciones competentes que viabilizarían la implementación de instrumentos económicos en el país. A su vez, a pesar de que para la ejecución óptima de un esquema de permisos de emisión éste debe ser habilitado por medio de una ley especial, podría explorarse su implementación simplificada mediante un sistema similar al establecido en el D.S. 4/1992 del Ministerio de Salud, avalado por el artículo 89 letra a) del Código Sanitario. 


\section{REFERENCIAS BIBLIOGRÁFICAS}

Bermúdez, Jorge. 2007. Fundamentos de derecho ambiental. Valparaíso: Ediciones Universitarias de Valparaíso.

Celaya, Rodolfo. 2002. "Naturaleza jurídica del permiso de emisión transable. Contemplado como instrumento económico en la Ley N. ${ }^{\circ}$ 19.300, de Bases Generales del Medio Ambiente". Revista Chilena de Derecho 29 (2): 315-366.

Chávez, Carlos. A. \& John K. Stranlund. 2000. "Effective Enforcement of a Transferable Emissions Permit System with a Self-Reporting Requirement". Journal of Regulatory Economics 18: 113-131.

Comisión Europea. 2009. Acción de la UE contra el cambio climático: El régimen de comercio de derechos de emisión de la UE. Luxemburgo, Oficina de Publicaciones Oficiales de las Comunidades Europeas. http://ec.europa.eu/ clima/sites/campaign/pdf/post_2012_es.pdf

Forte, Reynaldo, John Schakenbach \& Robert Vollaro. 2006. "Fundamentals of Successful Monitoring, Reporting, and Verification under a Cap-and-Trade Program". Journal of the Air \& Waste Management Association 56 (11): 1.576-83.

Goodkind, Andrew, Jay Coggins, Timothy Delbridge, Milda Irhamni, Justin Johnson, Suhyun Jung, Julian Marshall, Bijie Ren \& Martha Rogers. 2012. "Prices vs. Quantities with Increasing Marginal Benefitts". Draft paper, University of Minnesota.

Hatcher, Aaron, Shabbar Jaffry, Olivier Thébaud \& Elizabeth Bennett. 2000. "Normative and Social Influences Affecting Compliance with Fishery Regulations". Land Economics 76 (3): 448-461.

Hepburn, Cameron. 2006. "Regulation by Prices, Quantities, or Both: A Review of Instrument Choice". Oxford Review of Economic Policy 22 (2): 226-247.

Instituto Nacional de Estadísticas (INE). 2012. Cultivos anuales esenciales superficie sembrada año agrícola 2011/2012. http://www.ine.cl/canales/chile_estadistico/ estadisticas_agropecuarias/2012/superficie_sembrada_2011_2012.pdf

Kolstad, Charles D. 2011. Environmental Economics. Oxford: Oxford University Press.

Ministerio de Desarrollo Social (MDS). 2014. "Estimación del valor de los costos sociales por fallecimiento prematuro en Chile". División de Evaluación Social de Inversiones, Subsecretaría de Evaluación Social. http://sni. ministeriodesarrollosocial.gob.cl/doc/Validacion_Precios_Sociales_2014/ CostoFallecimientoPrematuro/Nueva_Propuesta_Valor_Costos_Sociales Fallecimiento_Prematuro_ChileSNI.pdf

Ministerio de Hacienda \& Ministerio de Medio Ambiente. 2014. "Estrategia nacional de crecimiento verde". http:/www.mma.gob.cl/1304/articles-55866_ Estrategia_Nacional_Crecimiento_Verde.pdf

Ministerio de Planificación (Mideplan). 2006. Encuesta CASEN 2006. http:// observatorio.ministeriodesarrollosocial.gob.cl/casen/casen_obj.php 
Ministerio del Medio Ambiente (MMA). 2011. "Guía metodológica. Inventario de emisiones atmosféricas M11 Metodología SINCA 2011”. Elaborado por Ambiosis. http://www.sinia.cl/1292/articles-52667_ GuiaMInventarioEmisionesAtmosfericas2011.pdf.

— 2013. "Análisis general de impacto económico y social del anteproyecto plan de prevención atmosférica Concepción metropolitano". Departamento de Economía Ambiental, Santiago de Chile.

Montero, Juan Pablo. 1999. "Voluntary Compliance with Market-Based Environmental Policy: Evidence from the Acid Rain Program". Journal of Political Economy 107 (5): 998-1033.

—. 2002. "Prices versus Quantities with Incomplete Enforcement". Journal of Public Economics 85: 435-454.

— 2004. "Markets for Environmental Protection: Design and Performance". Estudios de Economía 31: 79-99.

Montt, Santiago. 2002. El dominio público: estudio de su régimen especial de protección y utilización. Santiago: Conosur LexisNexis.

Organización para la Cooperación y Desarrollo Económicos (OCDE). 1999. Economic Instruments for Pollution Control and Natural Resources Management in OECD Countries. A Survey, Working Party on Economic and Environmental Policy Integration. http://www.oecd.org/officialdocuments/pu blicdisplaydocumentpdf/?doclanguage $=$ en $\&$ cote $=$ ENV/EPOC/GEEI(98)35/ REV1/FINAL

2012a. Recommendation of the Council on Regulatory Practices and Government. http://www.oecd.org/gov/regulatory-policy/49990817.pdf

- 2012b. Mortality Risk Valuation in Environment, Health and Transport Policies. http://www.oecd.org/env/tools-evaluation/mortalityriskvaluationinen vironmenthealthandtransportpolicies.htm

Organización para la Cooperación y Desarrollo Económicos \& Comisión Económica para América Latina (OCDE-Cepal). 2005. Environmental Performance Review, Chile 2005. http://www.oecd-ilibrary.org/environment/ oecd-environmental-performance-reviews-chile-2005_9789264009684-en

Parlamento Europeo y del Consejo. 2003. Directiva 2003/87/CE del Parlamento Europeo y del Consejo. http://eur-lex.europa.eu/LexUriServ/LexUriServ.do?u ri=OJ:L:2003:275:0032:0046:es:PDF

Pope, C. Arden, Richard Burnett, Michelle Turner, Aaron Cohen, Daniel Krewski, Michael Jerrett, Susan Gapstur \& Michael Thun. 2011. "Lung Cancer and Cardiovascular Disease Mortality Associated with Ambient Air Pollution and Cigarette Smoke: Shape of the Exposure-Response Relationships". Environmental Health Perspectives 119 (11): 1.616-21.

Saavedra, Eduardo \& Manuel Willington. 2012. "Eficiencia en asignación de cuotas individuales de pesca: teorema de Coase y asimetrías de información". Estudios Públicos 127.

Sánchez, José Miguel, Juan Pablo Montero \& Ricardo Katz. 2002. “A Market-based Environmental Policy Experiment in Chile". Journal of Law and Economics 45:267-287. 
Stavins, Robert. 1995. "Transaction Costs and Tradeable Permits". Journal of Environmental Economics and Management 29:133-148.

Tietenberg, Thomas H. 2006. Emissions Trading Principles and Practice. Washington D.C.: Resources for the Future.

Universidad de Concepción (UdC) - EULA. 2010. "Medidas para el control de la contaminación por combustión residencial de leña". Reporte encargado por Comisión Nacional del Medio Ambiente (Conama) Región del Bío-Bío, Concepción.

Universidad de Concepción (UdC) - Proterm. 2011. "Evaluación de medidas para reducir la contaminación atmosférica en complejos industriales y grandes fuentes del gran Concepción". Reporte encargado por Conama Región del Bío-Bío, Concepción.

US Environmental Protection Agency (USEPA). 1991. "Guidelines for Performing Regulatory Impact Analysis”. http://yosemite.epa.gov/ee/epa/eerm.nsf/a7a2ee 5c6158cedd852563970080ee30/6a7cbb45ab91395f8525643c007e4079?Open Document.

—. 2003. "Tools of the Trade: A Guide to Designing and Operating a Cap and Trade Program for Pollution Control”. http://www.epa.gov/airmarkt/resource/ docs/tools.pdf

—. 2010. "Control Strategy Tool, COST Equations Documentation". http:// www.epa.gov/ttn/ecas/models/Cost_Equations_Document_2010-07-07.pdf

Villena, Mauricio, Marcelo Villena \& Carlos Chávez. 2007. Análisis general de impacto económico y social del rediseño del plan operacional para enfrentar episodios críticos de contaminación atmosférica por material particulado respirable $\left(\mathrm{MP}_{10}\right)$ en la Región Metropolitana. Estudio realizado para Conama Región Metropolitana, Santiago.

Weitzman, Martin L. 1974. "Prices vs. Quantities". The Review of Economic Studies 41 (4): 477-491. 


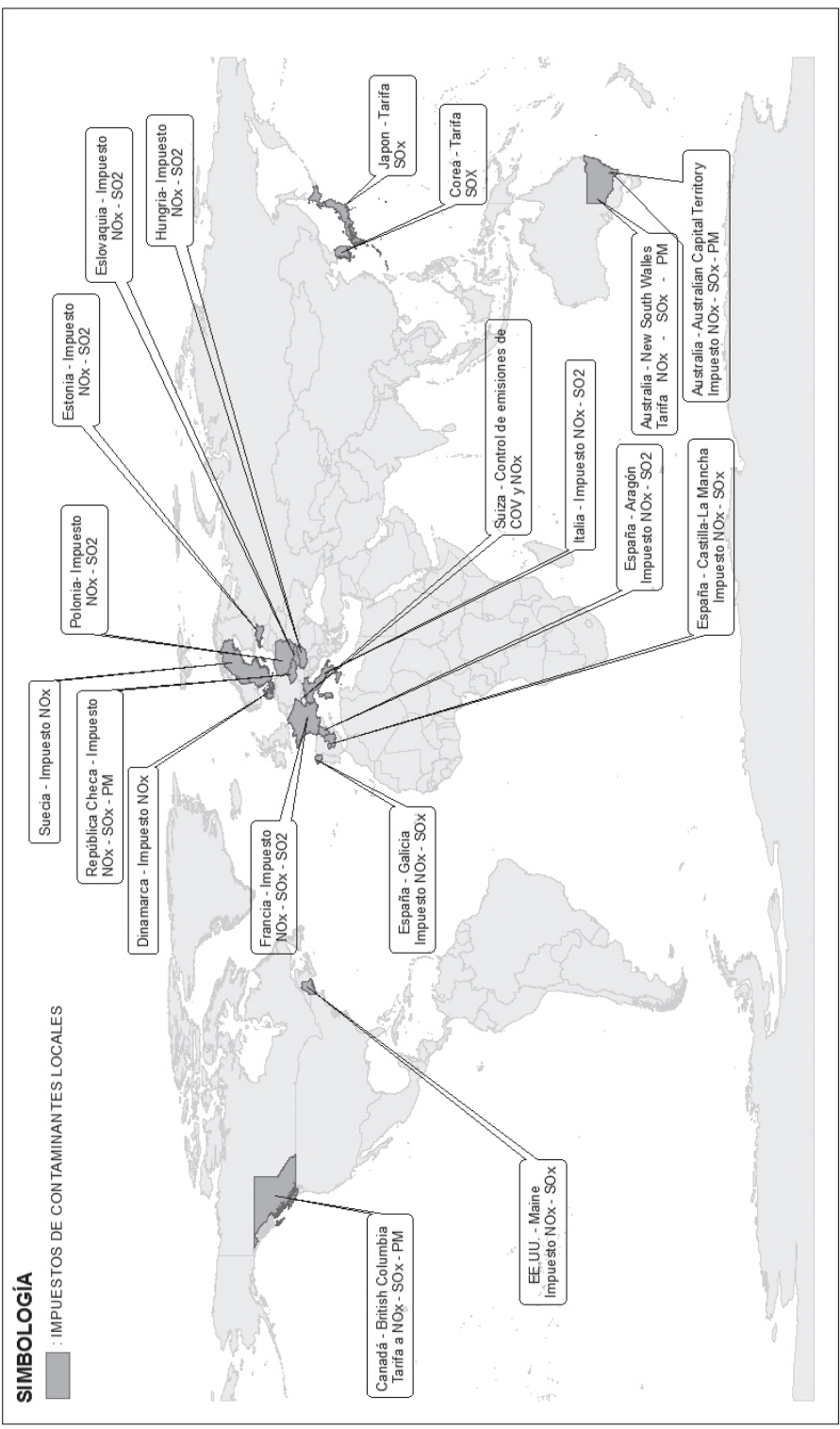

$\therefore: \frac{1}{\frac{0}{6}}$

ญै

गे

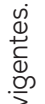

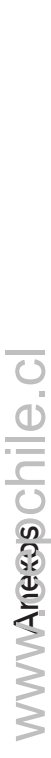




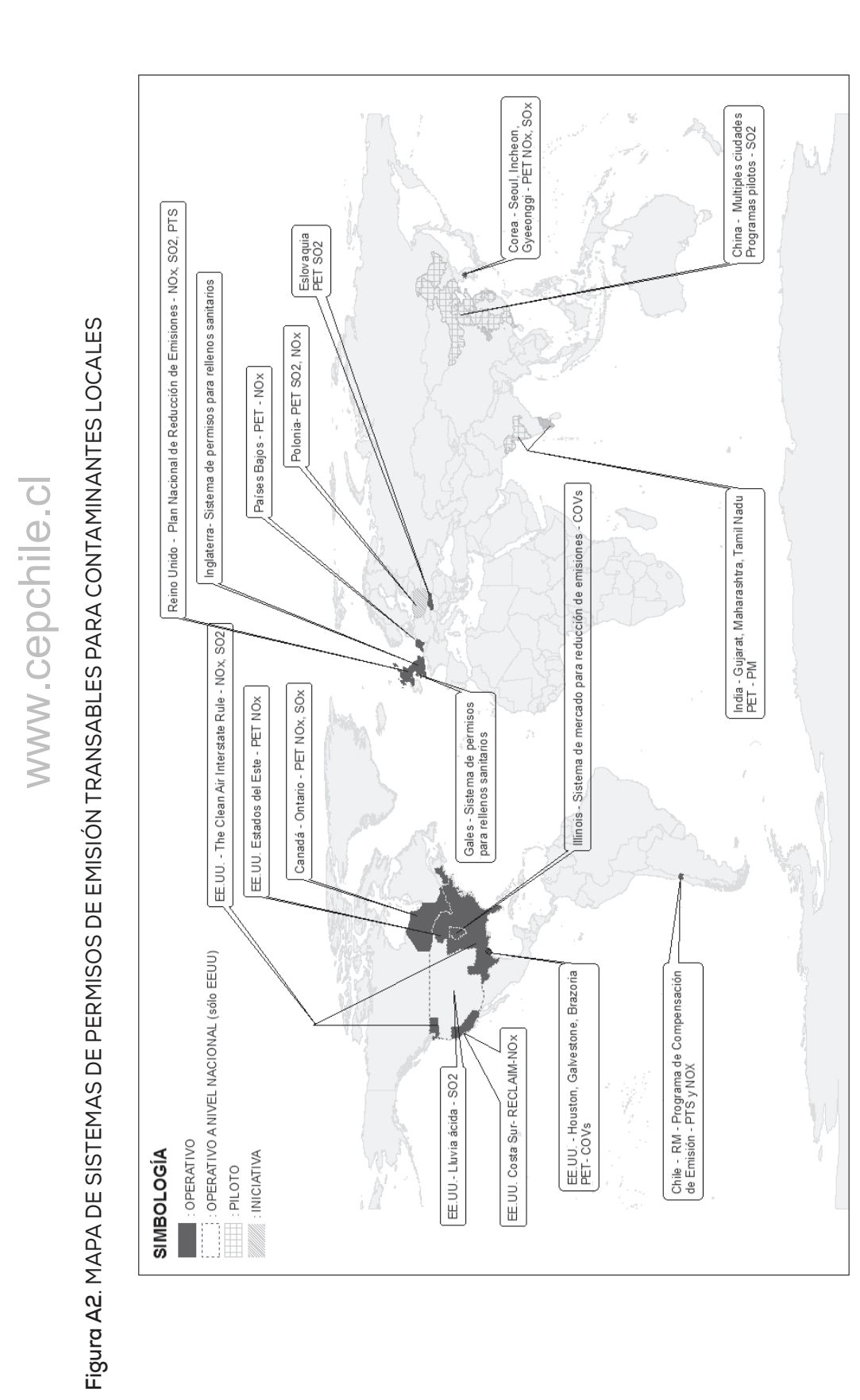

